\title{
A pragmatic approach to evaluate alternative indicators to GDP
}

\author{
L. Fasolo • M. Galetto • E. Turina
}

Published online: 16 July 2011

(C) Springer Science+Business Media B.V. 2011

\begin{abstract}
The serious economic crisis broken out in 2008 highly stressed the limitations of GDP used as a well-being indicator and as a predictive tool for economy. This induced the need to identify new indicators able to link the economic prosperity of a country to aspects of sustainable development and externalities, both positive and negative, in the long run. The aim of this paper is to introduce a structured approach which supports the choice or the construction of alternative indicators to GDP. The starting point is the definition of what a well-being indicator actually should represent according to the Recommendations of the Stiglitz-Sen-Fitoussi Report on the measurement of economic performance and social progress. Then the paper introduces a systematic procedure for the analysis of well-being indicators. The different phases of this procedure entail the checking of indicators technical properties and their effect on the representational efficacy. Finally, some of the most representative well-being indicators drawn from the literature are compared and a detailed application example is proposed.
\end{abstract}

Keywords Quality of life indicator · Well-being indicator - Sustainability indicator . GDP · Indicator properties

\section{Introduction}

The severe economic crisis broken out in the United States in 2008 and then rapidly propagated around the world, affecting both the financial and the real economy, has undermined the basis and the stability of the current economic system, including the GDP, which is one of its more representative indicators. The need to rethink the criteria for measuring the welfare of a country has arisen because there is an increasing gap between the information contained in aggregate GDP data and what is really important for common people's well-being (Stiglitz et al. 2009). It has long been clear that GDP is an inadequate metric to gauge well-being

L. Fasolo $\cdot$ M. Galetto $(\varangle) \cdot$ E. Turina

DISPEA, Politecnico di Torino, Corso Duca degli Abruzzi 24, 10129 Torino, Italy

e-mail: maurizio.galetto@polito.it 
over time particularly in its economic, environmental, and social dimensions, some aspects of which are often referred to as sustainability (Stiglitz et al. 2009; Bij1 2010).

The complexity in the measurement of the real welfare of a country has been investigated for many years by the most of well-known economists (Stiglitz et al. 2009). In 1934 Kuznets, the creator of the national accounts and hence GDP, warned that the welfare of a nation could not be measured simply by its index: the welfare of a nation can scarcely be inferred from a measure of national income (Kuznets 1934). In 1946 Hicks pointed out that the practical purpose of calculating income is to indicate the maximum amount people can produce and consume without undermining their capacity to produce and consume the same amount in the future (Hicks 1946). In 1973 Nordhaus and Tobin wondered if the GDP is not obsolete in their famous paper "Is growth obsolete?" (Nordhaus and Tobin 1973). Always in the Seventies, Sen considered the implicit treatment of income distribution as the main objection against GDP as a measure of welfare. An unequal distribution implies unequal opportunities for personal development and well-being (Sen 1976, 1979). Mishan (1967) and Daly (1977) asserted that GDP must be considered as an estimate of the total cost of all market-related economic activities in a country. In 2005 Stiglitz observed that no one would look at just a firm's revenues to assess how well it was doing. Far more relevant is the balance sheet, which shows assets and liabilities. That is also true for a country (Stiglitz 2005).

To explain paradoxes of GDP, the U.S. Senator R.F. Kennedy's, in his famous speech of March 1968 at the University of Kansas, said that this index measures everything in short, except that which makes life worthwhile (Kennedy 1968).

In 2008, during an audition to the US Senate, Jonathan Rowe highlighted some of the absurdities of mechanically measuring the economy by counting how much it produces. Measuring healthcare by inputs rather than outputs - the sale of medical services and drugs rather than the number of (healthy) people — can lead to particularly perverse perspectives.

The GDP is only a measure of production but it is a widespread practice to consider it as a measure of the progress in the people's welfare (D'Acci 2010). The level of production is important because it largely determines how much a country can afford to consume and it also affects the level of employment. The consumption of goods and services, both individually and collectively, is one of the most important factors influencing the welfare of a community, but it is only one of several factors. There are also others, such as epidemics, natural disasters or wars that can have major negative impacts on welfare, while others, such as scientific discoveries inventions, may have significant positive impacts. Since these factors do not directly enter into the measurement of GDP, movements of GDP on their own cannot be expected to be good indicators of changes in total welfare unless all the other factors influencing welfare happen to remain constant, which is never the case (United Nations Statistics Division 1993).

The GDP, also, pursues continuing growth and in this regard it is worth asking whether this corresponds to an improvement of welfare. A widespread practice is equating GDP to progress to justify its stimulus (Rojas 2010).

Economists highlighted the strong relations between costs and benefits in consequence of the increase of goods and services in a period of a country's growth (Daly and Cobb 1989; Lawn 2003). In this regard Max-Neef developed the so called "threshold hypothesis" (1995), the theory explaining that when macroeconomic systems expand beyond a certain size, the additional benefits of growth are exceeded by the attendant costs. Furthermore, in 1996 Hueting underlined that the growth of GDP is chiefly generated by the thirty percent economic activities that cause the major part of total environmental pressure. Costs incurred by the growth of the GDP may be, for example, the disturbance of ecological life-supporting systems, pollution, alienated labour, lost leisure time, and the loss of welfare for future generations (Brennan 2008). 
In February 2008, the President of the French Republic, Nicholas Sarkozy, unsatisfied with the present state of statistical information about the economy and the society, asked Joseph Stiglitz (President of the Commission), Amartya Sen (Advisor) and Jean Paul Fitoussi (Coordinator) to create a Commission, subsequently called "The Commission on the Measurement of Economic Performance and Social Progress" (CMEPSP). The Commission's purposes were (Stiglitz et al. 2009):

- to identify the limits of GDP as an indicator of economic performance and social progress, including the problems with its measurement;

- to consider what additional information might be required for the production of more relevant indicators of social progress;

- to assess the feasibility of alternative measurement tools, and to discuss how to present the statistical information in an appropriate way.

In November 2010, also the British Prime Minister David Cameron created a commission aimed at the development of a "happiness index" able to measure with apposite criteria and parameters the well-being of the British population.

The present paper focuses on this topical debate on the measurement of a country's welfare and on the limitations and paradoxes of GDP. It introduces a structured methodology for the analysis of well-being indicators alternative to GDP. The proposed procedure is based on formalized steps aimed at checking the technical properties of indicators. The methodology is intended to support decision-makers in the comparison of proposals of new indicators alternative to GDP.

This paper is organized as follows. Section 2 shows the approaches alternative to GDP and provides examples of indicators for each of them. Section 3 introduces the methodology for the analysis of indicators. Section 4 applies the first phase of the suggested procedure and verifies the compliance of a set of indicators alternative to GDP with the targets of the Stiglitz-Sen-Fitoussi Report. Section 5 develops the other phases of the methodology and synthetically shows the results of the comparison among the chosen indicators. Section 6 provides a detailed example of the methodology applied to a specific well-being index. Section 7 is reserved for conclusions.

\section{Alternatives to GDP for the measurement of economic and social development}

The inappropriateness of GDP as a well-being indicator is at least the direct consequence of the lack of a sufficiently clear and shared definition of well-being among international organizations and economic institutions, and the lack of shared operational tools developed to operationalize such a definition.

Over the years, many alternatives approaches to GDP have been introduced. They may be classified as (Van den Bergh 2007):

- Indicators based on rather pragmatic, accounting adjustments to GDP. These indicators represent a correction of the regular GDP by repairing important deficiencies through adding or subtracting certain amounts of money to/from GDP (see Sect. 2.1).

- Indicators entirely focused on environmental externalities and natural resource depletion. Corrections here give rise to "sustainable" or "green" GDP indicators (see Sect. 2.2).

- Indicators related to the distinction between measures of current well-being and measures of well-being over time (see Sect. 2.3). 
- Aggregated measures that combine indicators that are considered to capture relevant aspects of human well-being. Differently from the previous approaches, this one does not generate a monetary index (see Sect. 2.4).

In the following paragraphs some of the most remarkable examples of indicators for each of these approaches are proposed.

\subsection{Indicators based on accounting adjustments to GDP}

\subsubsection{Measure of Economic Welfare (MEW, Nordhaus and Tobin 1973)}

The MEW is the first version of modified National Income Index and was constructed by Nordhaus and Tobin (1973) in order to reflect more completely the economic welfare. Three kinds of modifications were introduced. First of all, expenditures with regard to health care and education were treated as investment in human capital whereas expenditures on police and on defence were treated as "intermediate" thus not in themselves generating welfare (Lintott 1996). Second of all, items with regard to the services of capital goods such as durable consumer goods or leisure time were added. Finally, costs of urbanisation were subtracted. The UN System of National Accounts defined MEW as an adjusted measure of total national output, including only the consumption and investment items that contribute directly to economic well-being, calculated as additions to gross national product (GNP), including the value of leisure and the underground economy, and deductions such as environmental damage (Kulig et al. 2007).

\subsubsection{Index of Sustainable Economic Welfare (ISEW, Daly and Cobb 1989) and Genuine Progress Indicator (GPI, Cobb et al. 1995)}

The ISEW has been developed by Daly and Cobb (1989) to integrate environmental and social externatilities in national welfare accounting. With some modifications to the original accounting method, the ISEW has been relabelled to the Genuine Progress Indicator (Cobb et al. 1995). Both the GPI and ISEW use the same personal consumption data as GDP but make both deductions (e.g.: costs of crime, environmental degradation, loss of leisure) and additions to account (e.g.: benefits of volunteering and housework). By differentiating between economic activity that diminishes both natural and social capital and activity that enhances such capital, the GPI and its variants are designed to measure sustainable economic welfare rather than economic activity alone (Talberth et al. 2007). The distribution of income and wealth is evaluated by Gini Coefficient (Kimura 1994). Although the ISEW is currently calculated for some countries, these calculations were done by very different institutions and are hardly comparable (Böhringer and Jochem 2007).

\subsection{Indicators based on "green" correction to GDP}

\subsubsection{Sustainable National Income (SNI, Hueting 1974)}

In Hueting opinion (1974) the SNI is the maximum net income which can be sustained on a geological time scale. The SNI approach uses a general equilibrium model that calculates the impact on national income of imposing sustainability constraints for the most important environmental themes. The idea of Hueting is to estimate the costs for the conservation of the natural environment and then subtract them from the NNI (Net National Income). The gap between NNI and SNI measures the part of production unsustainable. 


\subsubsection{Green Net National Product or Environmentally Adjusted Net Domestic Product (EDP, UNEP 2000)}

The Green National Product or likewise the Environmental Adjusted Net Domestic Product has been developed within the scope of SEEA (System of integrated Environmental and Economic Accounting) (UNEP 2000). Three different versions of EDP exist: the EDP-I which subtracts depreciations of natural resources from the NNI, the EDP-II, which subtracts from the NNI the costs necessary to reach the same state of the environment at the end of the period as existed at the beginning of the period, and the EDP-III, which subtracts the costs of environmental pressure and destruction (calculated by willingness-to-pay methods) (Böhringer and Jochem 2007).

\subsection{Indicators related to the distinction between measures of current well-being} and measures of well-being over time

\subsubsection{Genuine Saving (GS, Hamilton et al. 1997) or Adjusted Net Savings (ANS, World Bank 1997)}

The GS indicator proposed by Hamilton et al. (1997) modifies the first proposal of Pearce and Atkinson (1993) and is based on the Hartwick rule (1977) which defines the level of re-investment from resource rents that are reinvested to assure that the societal capital stock will never decline. The GS is a weak sustainability indicator in that it allows for substitution of nature and natural resources by production and human capital. It can be defined as traditional net savings subject to a number of corrections (Bolt et al. 2002): (i) the value of depletion of natural resources is deducted; (ii) the costs associated with pollution damage, including economic and health effects, are deducted; (iii) expenditures on education are treated not as consumption but as savings/investments in human capital and thus added; (iv) net foreign borrowing is deducted, while net official transfers are added; (v) capital depreciation (capital consumption) is deducted (Van den Bergh 2007). The GS has been adopted as a central indicator by the World Bank under the name of Adjusted Net Savings.

\subsection{Aggregated indicators aimed at capturing relevant aspects of human well-being}

\subsubsection{Human Development Index (HDI, United Nations Development Programme 2003)}

The Human Development index (HDI) by the United Nations aggregates a number of indicators: GDP per capita (in Purchasing Power Parity), life expectancy at birth, adult literacy rate, and combined primary, secondary, and tertiary gross enrolment ratios (Smith 2009). The incorporation of GDP reflects, through a log-transformation and a maximum income limit, a decreasing marginal utility of income. Nevertheless, the HDI is quite arbitrary in the selection of its components and in the aggregation procedure (Van den Bergh 2007; Franceschini et al. 2007).

\subsubsection{Well-being Index (WI, Prescott-Allen 2001)}

The Well-Being Index by Prescott-Allen (2001) is based on the assumption that a healthy environment is necessary for healthy humans. Accordingly, the WI is the arithmetic mean of 
a Human Well-Being Index (HWI) and an Ecosystem Well-Being Index (EWI). The indices HWI and EWI in turn consist of five sub-indices. The HWI comprises a Health and Population, Welfare, Knowledge, Culture and Society, as well as an Equity Index. The EWI comprises indices for land, water, air, species and genes as well as for resources deployment. The five dimensions of the HWI are based on 36 indicators, those of the EWI on 51 indicators (Prescott-Allen 2001).

\subsubsection{Sustainable Society Index (SSI, Van de Kerk and Manuel 2008)}

The SSI aims to integrate the most important aspects of sustainability and quality of life of a national society in a simple and transparent way (Van de Kerk and Manuel 2008). It was launched in 2006 and updated in 2010 on the basis of the Stiglitz-Sen-Fitoussi Report; it consists of 24 indicators, grouped into 8 categories (Basic Needs, Personal Development, Well-balanced Society, Healthy Environment, Climate \& Energy, Natural Resources, Preparation for the Future, Economy) (Sustainable Society Foundation 2010).

\section{A methodology for the analysis of economic and social development indicator}

The aim of this Section is to present a method of analysis able to support the choice and implementation of well-being indicators.

Before describing in detail the suggested methodology, some key notions related to the concept of indicator must be reminded (Franceschini et al. 2007).

The definition of indicator is strictly related to the concept of "representation-target". A representation-target is the operation aimed at making a "context", or parts of it, "tangible" in order to perform evaluations, make comparisons, formulate predictions, take decisions, etc... A context may be, for example, a manufacturing process in the field of the production management, a distribution/supply chain in the field of logistics, a market with regard to business management. Given a context, one or more different representation-targets can be defined. Indicators are tools which operationalize a representation-target, referring to a given context (Franceschini et al. 2007). Depending on the context, a given representation-target may be operationalized by a single indicator or a set of indicators. Furthermore, indicators may be basic or derived (i.e. indicators obtained by the aggregation of two or more sub-indicators).

In this paper the context is represented by the economic and social development of a country while we assume as representation-target the Stiglitz-Sen-Fitoussi Report's Recommendations (see Sect. 4).

The proposed methodology refers to derived indicators which is the form of the most of the alternatives to GDP. However, the same guidelines can be extended to single indicators and, even if with some precautions, to set of indicators. It is divided into the following phases:

\subsection{Phase 1-definition of representation-target}

A well-defined and shared representation-target is an indispensable prerequisite to select and analyze the existing well-being indicators or to define new ones.

At present, the Stiglitz-Sen-Fitoussi Report seems able to meet this need in a very authoritative, competent and comprehensive way, both for the great attention paid to the different stakeholders' issues and to the multidimensional approach to the concept of well-being (Natoli and Zuhair 2010). 
3.2 Phase 2-analysis of the construction models

Phase 2 aims to identify the different aggregation models the sub-indicators are gradually aggregated by into a single derived indicator and the related number of aggregation levels.

Identifying the different types of aggregation models (e.g.: additive models, geometric aggregations, minimum or maximum operator, ...) is useful to observe possible compensatory effects at the level of aggregated indicator. Moreover, when weighted average is applied, the definition of weights of component indicators is very critical. The choice of weights is subjective in nature and there is no prescribed rules for weighting data (Natoli and Zuhair 2010).

In addition, the changing of the construction algorithms of sub-indicators over time may affect the comparability among indicators.

Finally, knowing the number and contents of the different aggregation levels is fundamental to understand the meaning of the final value of the aggregated indicator.

\subsection{Phase 3-analysis of the scales of assessment}

This analysis is essential to verify if the operations carried out on indicators are consistent with the properties of the used measurement scales. In the considered context, aggregated as well component indicators are often obtained by normalization, interpolation or other specific algorithms. For example, if data are expressed on nominal or ordinal scales, the first two operations are not possible (Roberts 1979). The application of non proper operations to data may affect negatively the reliability of the ranking of countries according to a given well-being indicator and the comparability over time (Franceschini et al. 2007).

Finally, it is important to understand if an aggregated indicator or its components are expressed on a subjective or objective scale. This analysis is basic to interpret the collected data especially for the considered context since the measurement of well-being includes several subjective elements (D'Acci 2010).

\subsection{Phase 4—checking of correlation/independence among sub-indicators}

Two indicators are defined as correlated if variations on the first one determine variations on the second one and vice versa (Franceschini 2002). In the considered context some component indicators may include a partially overlapping information but, due to the lack of more reliable alternative indicators, they are used anyway (Sustainable Society Foundation 2010).

However, the presence of correlation must be carefully identified since it may induce a counter productive effect on the aggregated indicator (Franceschini et al. 2007).

If the increase of a specific source indicator $\left(I_{k}\right)$ is associated with the decrease of one or more indicators (for example $I_{i}, I_{l}, I_{m}$ ), determining a decrease of the global performance $\left(I_{T O T}\right)$ too, then $\left(I_{k}\right)$ is counter-productive (Franceschini et al. 2007).

\subsection{Phase 5-checking of monotony property}

If the increase/decrease of one sub-indicator is not associated to the increase/decrease of the aggregated indicator, then the aggregated indicator does not fulfil the condition of monotony. In formal terms (Franceschini et al. 2007): 


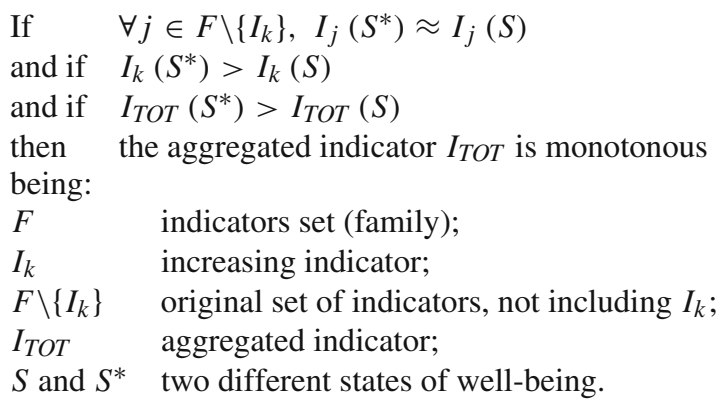

In the analysis of well-being indicators cases where the non-monotony property may be critical must be identified (for more details see the example of Sect. 6).

\subsection{Phase 6-checking of compensation property}

If changes of sub-indicators compensate each other-without making the aggregated indicator value change - then the aggregated indicator fulfils the property of compensation. In formal terms, a derived indicator $\left(I_{T O T}\right)$ fulfils the property of compensation if the following condition is verified (Franceschini et al. 2007):

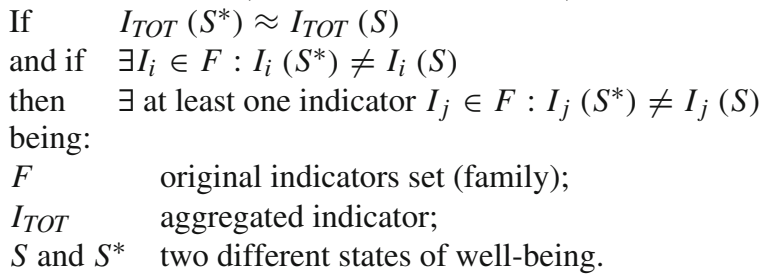

Additive models often used in the evaluation of well-being indicators satisfy the property of compensation. As a consequence, there is a substitution effect among component indicators. Cases where the compensation is critical must be then identified (for more details see the example of Sect. 6).

\subsection{Phase 7—checking of other general properties and accessory properties}

Other properties to be investigated are (Franceschini et al. 2007):

\subsubsection{General properties}

Level of detail (resolution): the indicator should not provide more than the required information. An indicator with excessive level of detail could be economically wasteful while, on the other hand, an indicator with a lower resolution than the required could lost important information on phenomenon investigated.

Economic Impact: each indicator should be defined considering a reasonable trade-off between the accuracy required to the information and the related expenses to collect them.

Simplicity of use: indicators should be easy to understand, easy to use, largely accepted and have a clear meaning.

\subsubsection{Accessory properties}

Long term goals: indicators and representation-targets should encourage the achievement of long term-goals. 


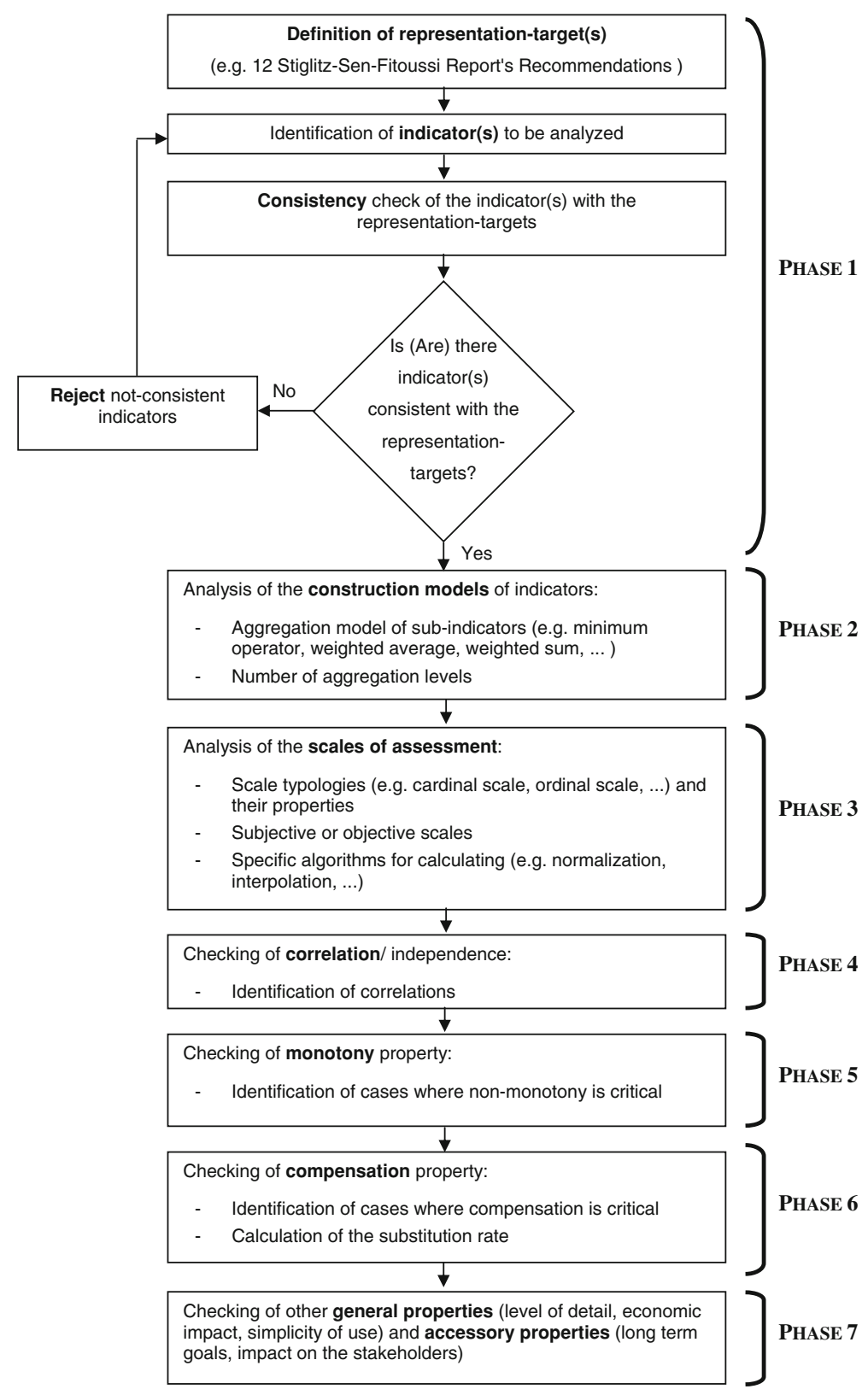

Fig. 1 Flowchart of the proposed methodology of analysis

Impact on the stakeholders: for each indicator the impact on process stakeholders should be carefully analysed. In the field of well-being evaluation the main stakeholders are, obviously, the citizens.

A scheme of the proposed methodology of analysis is reported in Fig. 1. 


\section{Representation-target}

GDP was never meant to be an indicator of wellbeing but it assumed this role in the absence of more representative indicators. However, we manage what we measure, and without new measures of societal progress, we are going to be ill-equipped to direct our efforts towards achieving a more sustainable and equitable wellbeing (OECD 2009). According to this, the Stiglitz-Sen-Fitoussi Report presents a series of messages and recommendations to define an alternative to GDP. Well-being is defined as multidimensional and the main dimensions to be considered are:

- Material living standards;

- Health;

- Education;

- Personal activities, including work;

- Political voice and governance;

- Social connections and relationships;

- Environment (present and future conditions);

- Insecurity, of an economic as well as physical nature.

Given the comprehensiveness and the authoritative sources of the Report's Recommendations, we adopt them as a rigorous formalization of the representation-target for the economic and social development of a country.

In Table 1, some of the most significant indicators alternative to GDP and proposed in the scientific literature are analyzed in order to verify if they meet the Report's Recommendations.

\section{Comparison among the investigated indicators}

After the analysis on the consistency of indicators with the established representation-target (Phase 1), the proposed methodology entails the checking of their technical properties (Phases 2-7).

In Table 2 the main outputs of the comparison among the selected indicators alternative to GDP are reported. In this analysis, indicators based on "green" correction to GDP, as the SNI and the EDP, are not considered because completely inconsistent with the representation-target (see Table 1).

Observing Table 2 we can see that all the indicators are aggregated by means of an additive model. Moreover, we note that indicators based on accounting adjustments to GDP (like the MEW and the GPI) and the GS are expressed in dollars since they result from ad hoc procedures to monetize positive and negative externalities. Aggregated indicators such as the HDI, the WI and the SSI are instead normalized and expressed on a [0-10] or [0-100] scale. This operation may affect the comparability among indicators given the arbitrariness of some parameter of the algorithms of normalization as better explained in the example of Sect. 6.

The number of levels of aggregation vary among the considered indicators. At the increasing of these levels, a given value of the aggregated indicator of well being is more difficult to interpret. Consequently, for decision-makers it is very critical to identify how to improve a country's well-being.

Correlation is present among some of the sub-indicators so its possible effect (i.e. counterproductivity) on the overall aggregation should be deeply investigated.

The property of monotony is not satisfied by the WI. 


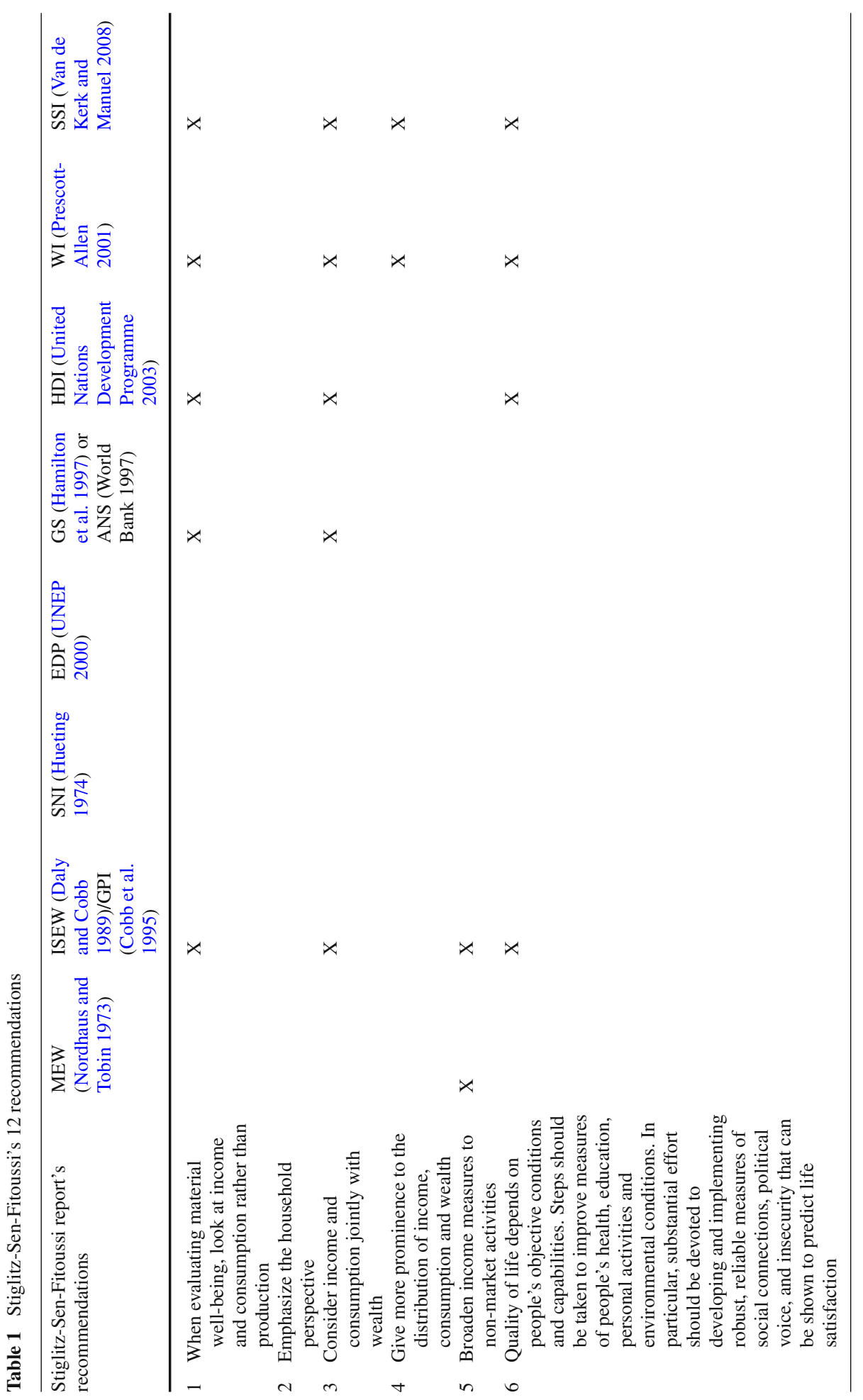




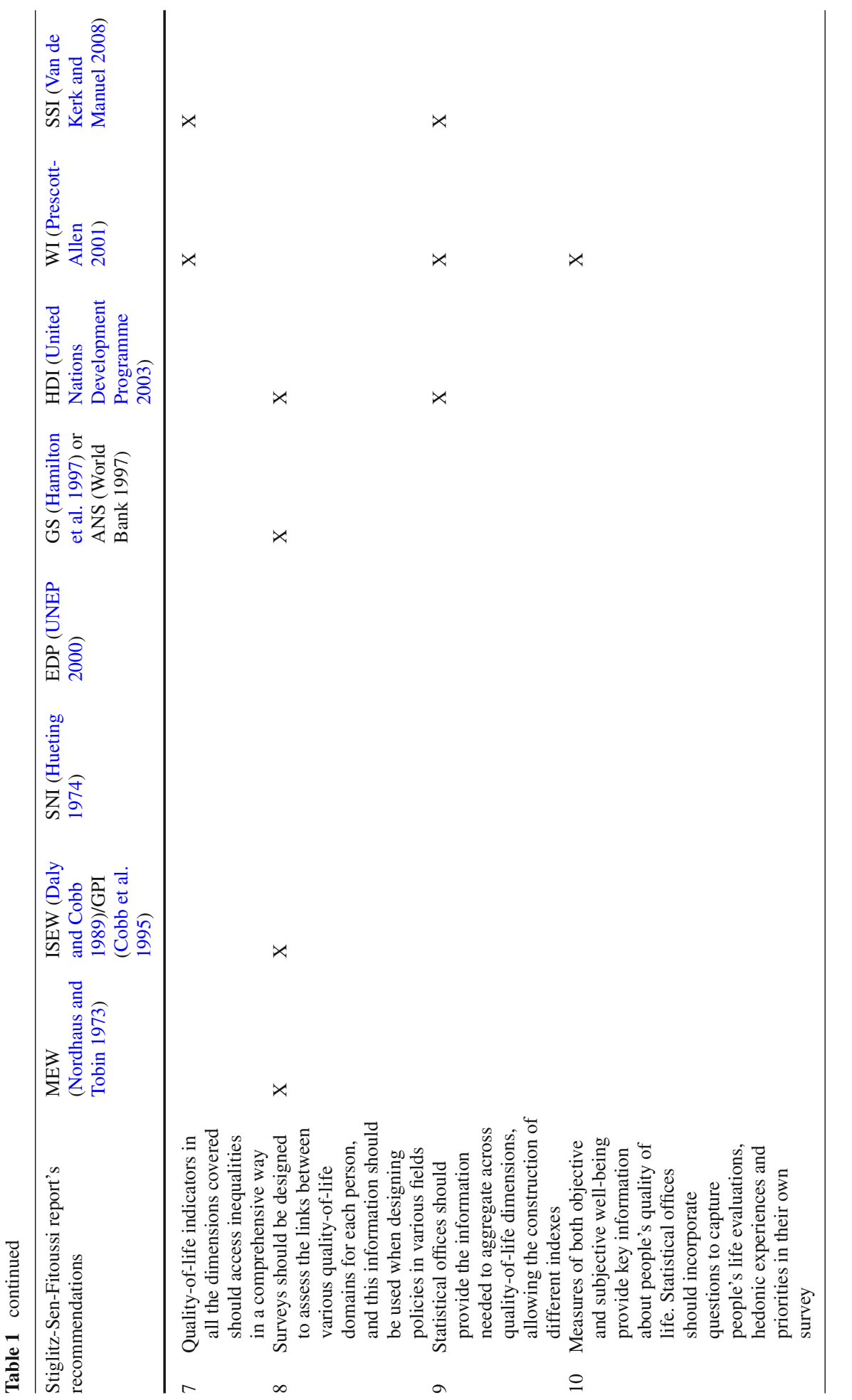

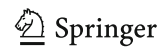




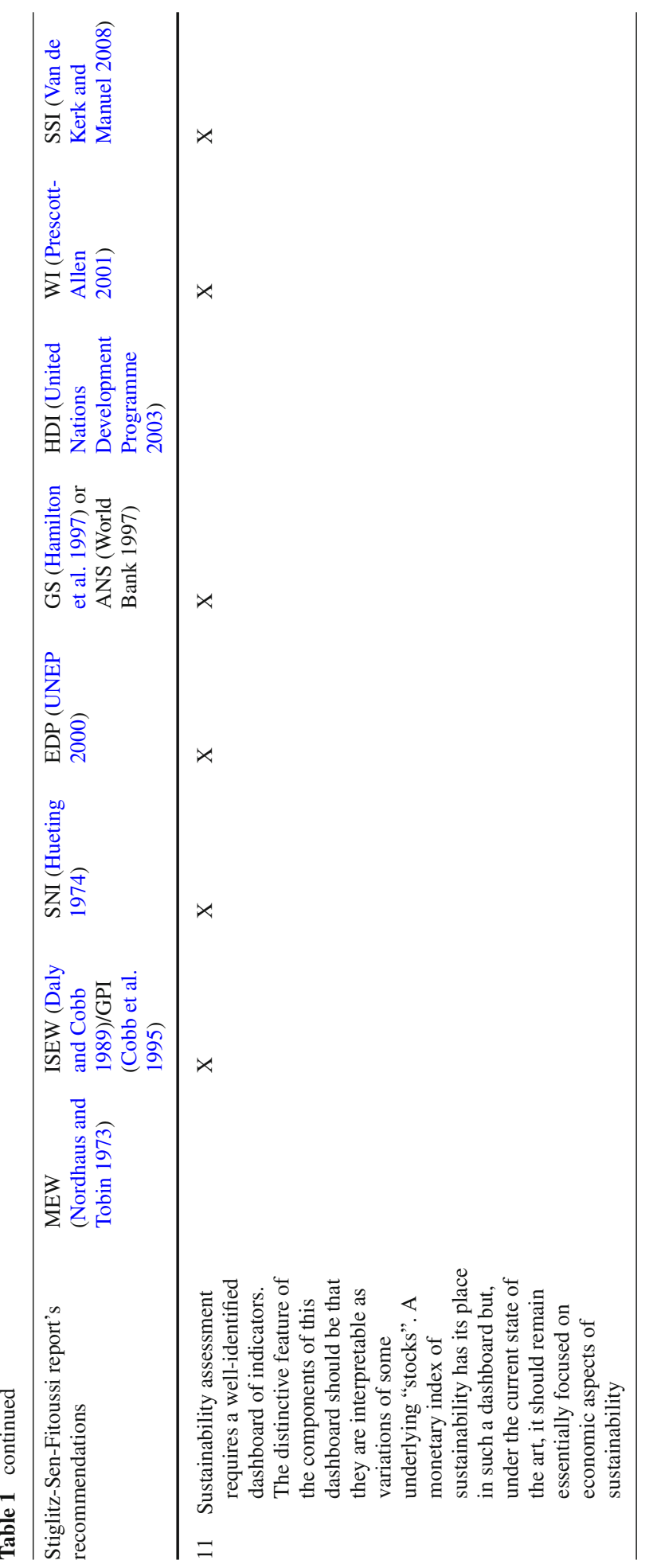




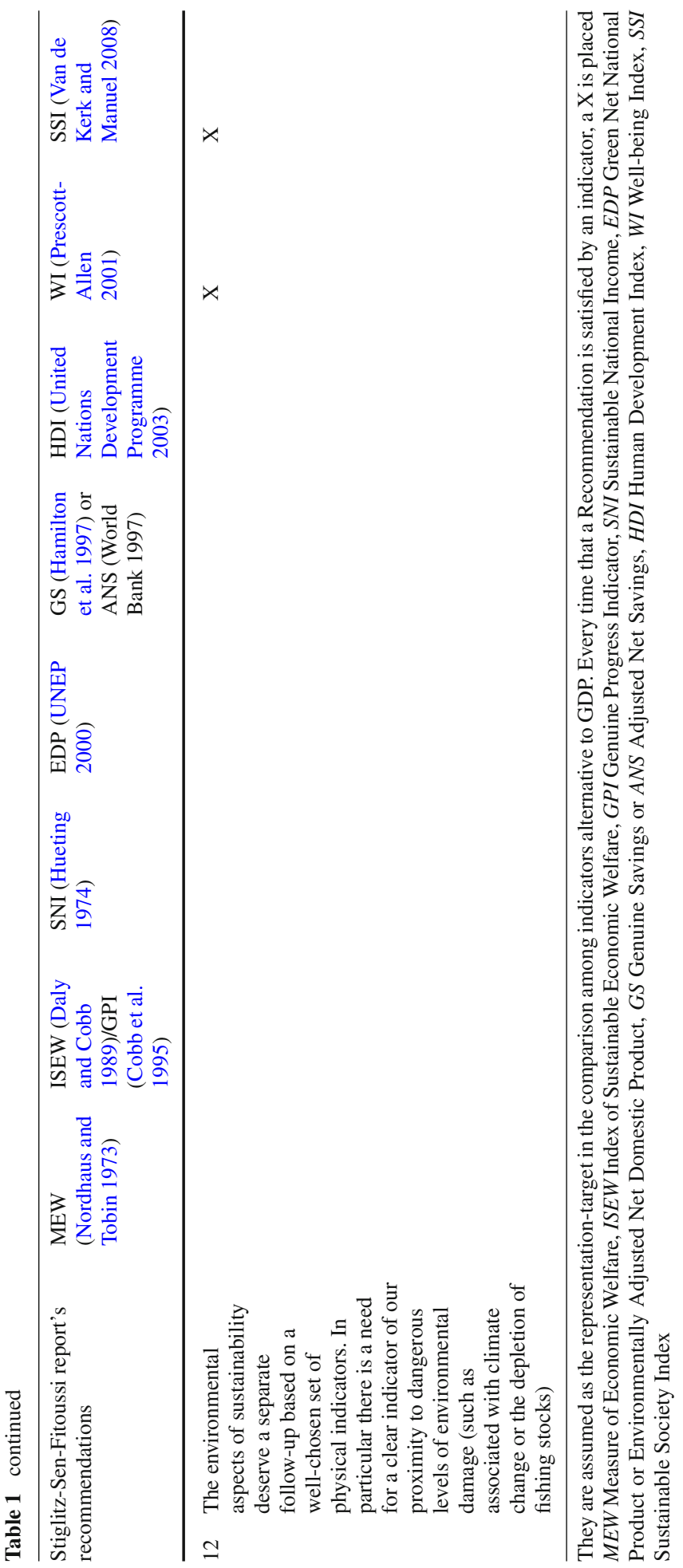

를 Springer 


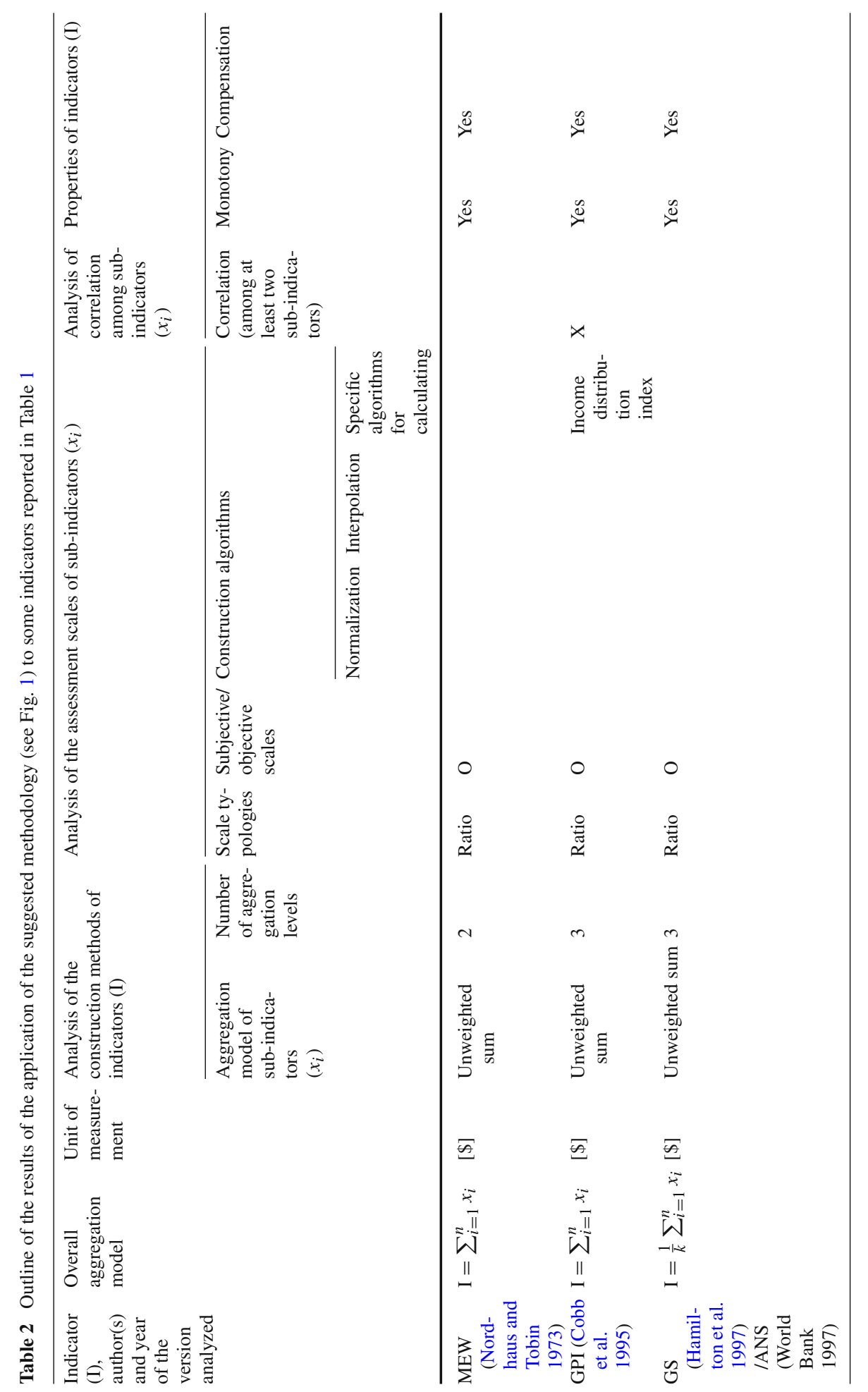




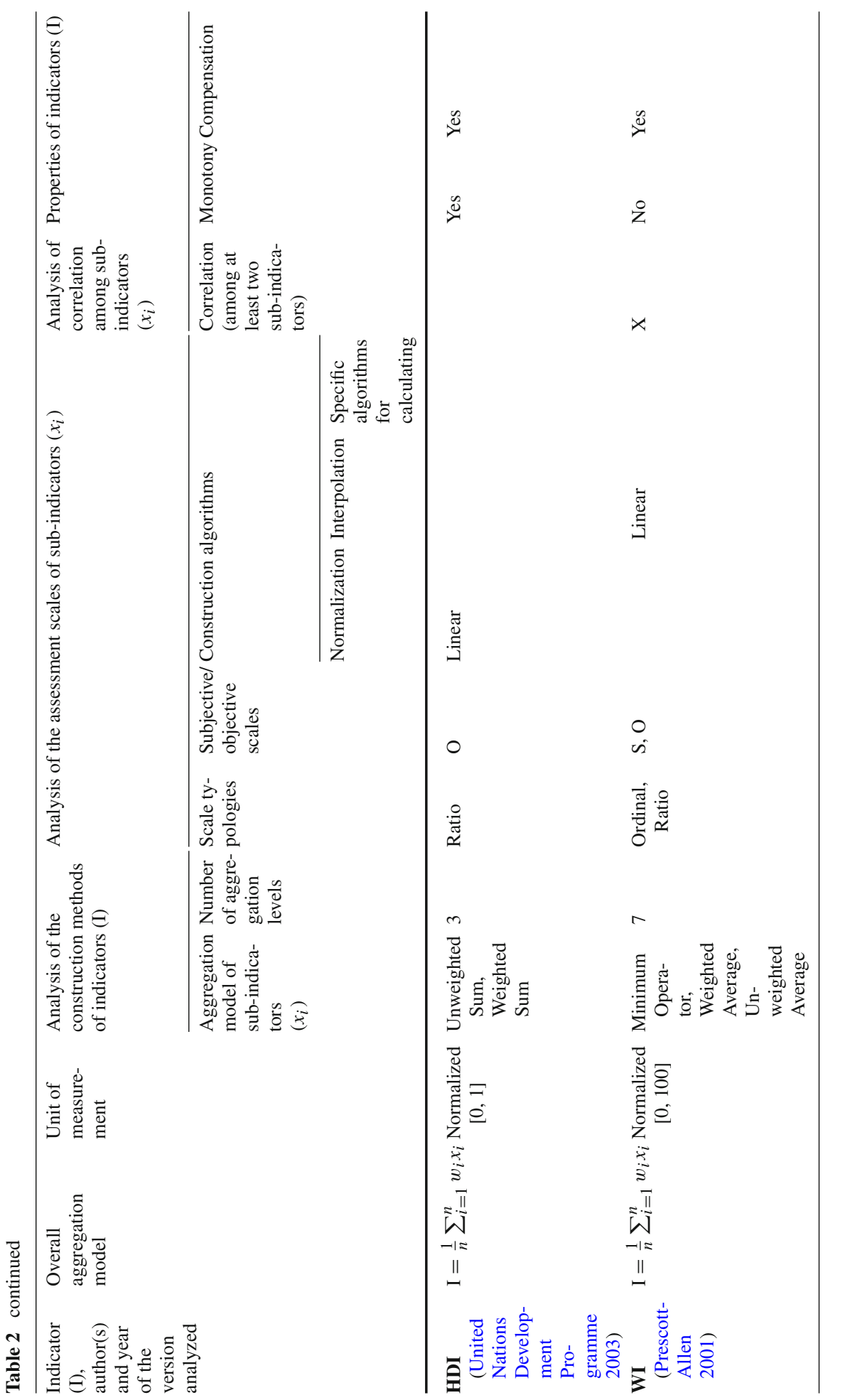




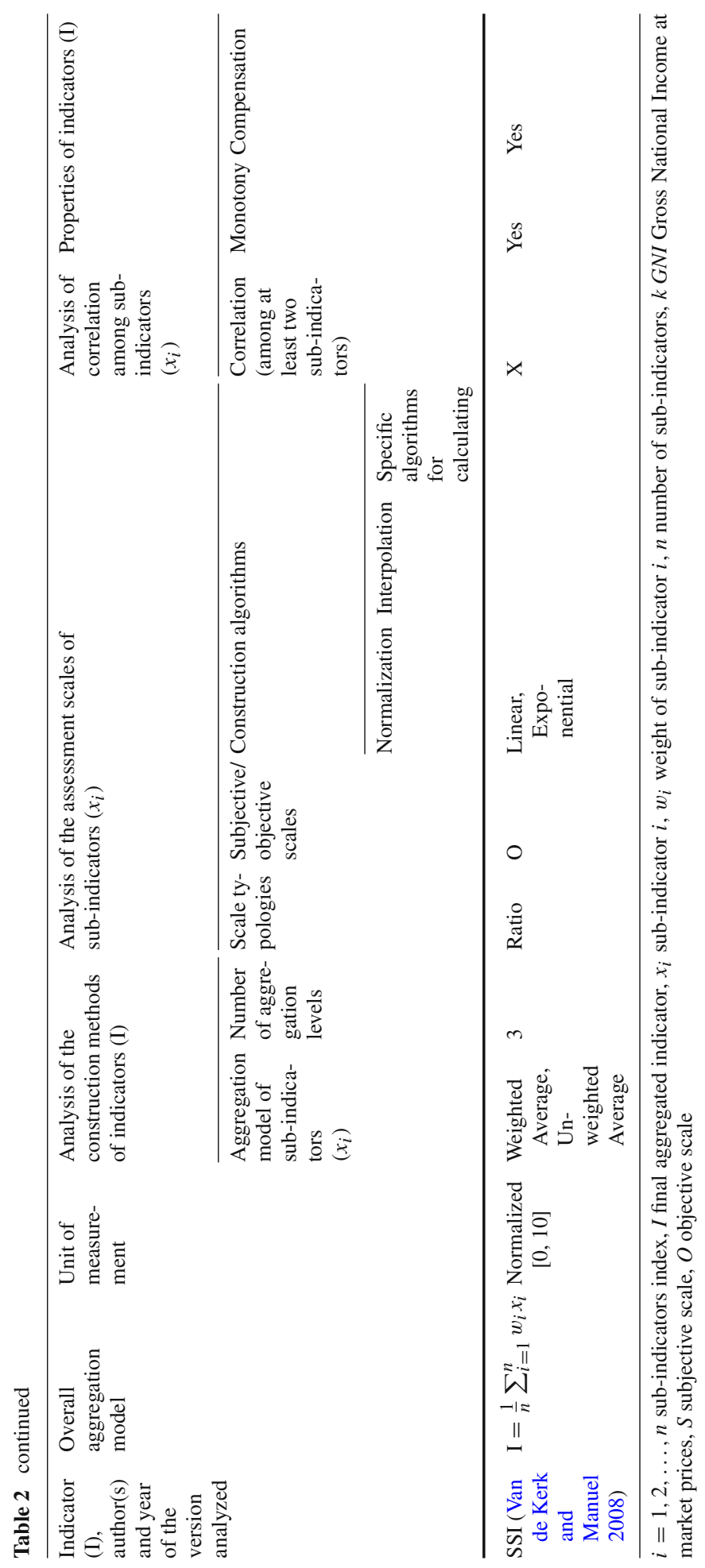


Table 3 The five bands of the barometer of sustainability (Prescott-Allen 2001)

\begin{tabular}{lll}
\hline Band & Range of points & Definition of band \\
\hline Good & $81-100$ & Desirable performance, objective fully met \\
Fair & $61-80$ & Acceptable performance, objective almost or barely met \\
Medium & $41-60$ & Neutral or transitional performance \\
Poor & $21-40$ & Undesirable performance \\
Bad & $1-20$ & Unacceptable performance \\
Base & 0 & Base of scale \\
\hline
\end{tabular}

The property of compensation is satisfied by all indicators since they are obtained whit an additive aggregation model. In general, a common implicit assumption of weak sustainability closely related to a concept of perfect substitutability among the different forms of capitals (physical, human, natural, ...) is present in all the considered indicators. In Sect. 6 an example on the calculation of the substitution rate will be given.

For the sake of simplicity, comments on general and accessory properties are not reported in Table 2. The evaluation of well-being requires a multidimensional approach (see Sect. 4) but indicators characterized by a very large number of sub-indicators (like the SSI and the WI) often provide an excessive level of detail very difficult to interpret.

Referring to the economic impact, it is essential to analyze the trade-off between the accuracy required to the information and the related expenses to collect them. The SSI is particularly worthy of attention, since its authors extract the different sub-indicators from public domain's sources in order to obtain transparent and low cost information.

The simplicity of use may influence the adoption of an indicator. In this regard, the monetization of positive and negative externalities, characterizing indicators based on accounting adjustments to GDP (like the MEW and the ISEW or the GPI), often makes them difficult to evaluate and understand (Natoli and Zuhair 2010).

The GS is the indicator, among the investigated, that best focuses on long term goals related to a country well-being, because it is the only one built on the capital stocks (produced, human and natural) suggesting then a long-run perspective.

\section{An application example: the Well-being Index (WI, Prescott-Allen 2001)}

In order to provide an application example of the proposed methodology, in the following the procedure is developed for the Well-being Index (Prescott-Allen 2001).

\subsection{Construction model of the WI}

The WI is calculated as the arithmetic mean of HWI (Human Well-being Index) and EWI (Ecosystem Well-being Index) in order to rank different countries (see Sect. 2.4).

The Well Being Index ranges from 0 to 100 on a scale called Barometer of Sustainability where different bands are identified (see Table 3 ).

In details, the WI is obtained from 87 indicators called scores which are progressively aggregated in the EWI and HWI. Figure 2 reports an extract of the pattern of aggregation. We may observe that derived indicators are obtained from scores with different aggregation procedures (e.g. average, $\min / \max$ operators, ...). 


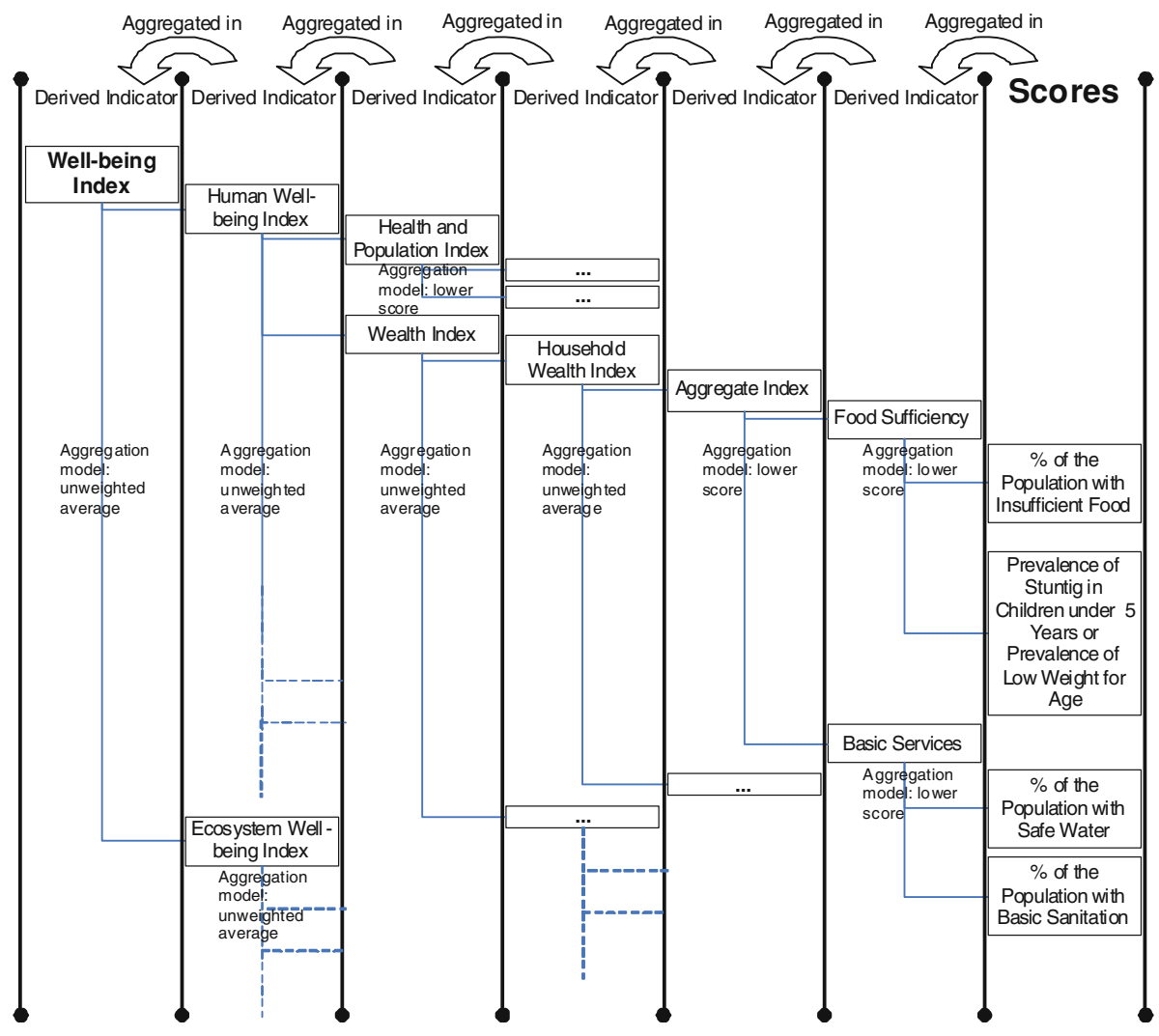

Fig. 2 Extract of the pattern of aggregation of the WI

Each score $\mathrm{I}_{p}$ is also expressed on the Barometer scale and obtained through the linear interpolation of a basic indicator:

$$
\mathrm{I}_{p}=\mathrm{I}_{L, p}+\frac{I_{H, p}-I_{L, p}}{S_{H, p}-S_{L, p}}\left(\mathrm{X}_{p}-\mathrm{S}_{L, p}\right) \in(0,100)
$$

where $\mathrm{X}_{p}$ is the actual basic indicator value, $\mathrm{S}_{H, p}$ is the top basic indicator value, $\mathrm{S}_{L, p}$ is the base basic indicator value, $\mathrm{I}_{H, p}$ is the top point of the band on the Barometer Scale, $\mathrm{I}_{L, p}$ is the base point of the band on the Barometer Scale.

The formula above is applied when best is the highest value of $\mathrm{X}_{p}$ and worst is the lowest. On the opposite, we have:

$$
\mathrm{I}_{p}=\mathrm{I}_{H, p}-\frac{I_{H, p}-I_{L, p}}{S_{H, p}-S_{L, p}}\left(\mathrm{X}_{p}-\mathrm{S}_{L, p}\right) \in(0,100)
$$

For example, the score of "Women's share of seats in Parliament" (a component of the HWI) for Netherlands in 2006 is calculated in the following way (see Table 4):

$$
\mathrm{I}_{p}=60+\frac{80-60}{40-30}(39-30)=78
$$


Table 4 Bands of the barometer of sustainability for the indicator 'Women's share of seats in Parliament' (Prescott-Allen 2001)

\begin{tabular}{lll}
\hline $\begin{array}{l}\text { Top values on basic } \\
\text { indicator scale }\end{array}$ & $\begin{array}{l}\text { Top points on } \\
\text { barometer scale }\end{array}$ & Bands \\
\hline 50 & 100 & Good \\
40 & 80 & Fair \\
30 & 60 & Medium \\
20 & 40 & Poor \\
10 & 20 & Bad \\
0 & 0 & Base \\
\hline
\end{tabular}

Table 5 Effect of the definition of scale limits on the comparability of indicators over the years

\begin{tabular}{|c|c|c|c|}
\hline \multicolumn{4}{|c|}{ Women's share of seats in parliament } \\
\hline $\begin{array}{l}\text { Top values on } \\
\text { basic indicator } \\
\text { scale (old) }\end{array}$ & $\begin{array}{l}\text { Top values on } \\
\text { basic indicator } \\
\text { scale (new) }\end{array}$ & $\begin{array}{l}\text { Top points on } \\
\text { barometer scale }\end{array}$ & Bands \\
\hline 50 & 50 & 100 & Good \\
\hline 40 & 40 & 80 & Fair \\
\hline 30 & 35 & 60 & Medium \\
\hline 20 & 20 & 40 & Poor \\
\hline 10 & 10 & 20 & Bad \\
\hline 0 & 0 & 0 & Base \\
\hline \multicolumn{4}{|c|}{$X p(2009)=31 \%$} \\
\hline \multicolumn{4}{|c|}{$X p(2010)=31 \%$} \\
\hline \multicolumn{4}{|c|}{ Ip $(2009$ - old scale limits $)=62$ (Medium, Fair) on the barometer scale } \\
\hline \multicolumn{4}{|c|}{ Ip $(2010$ - new scale limits $)=55$ (Poor, Medium) on the barometer scale } \\
\hline
\end{tabular}

Source of data for basic indicators: Inter-Parliamentary Union database (survey of 31 May 2009 and 31 May 2010)

Source of Top values on basic indicator scale (old): Prescott-Allen (2001)

The value of $\mathrm{X}_{p}=39 \%$ is extracted from the Inter-Parliamentary Union database. For Netherlands, on the basis of the Barometer of sustainability, we may say that the level of participation of women in politics is in the band "Fair-Good" (Table 4).

\subsection{Assessment scales}

A first criticality concerns the definition of top values on basic indicators scale for the calculation of scores. Their variation may affect the comparability over the years of countries. For example, with regard to the indicator "Women's Share of Seats in Parliament", assuming that after some years the participation of women in politics increases, it is reasonable to suppose that the limits of scale will be modified. Table 5 reports a possible variation of top values on basic indicators scale and the effect on the score of Germany. Even if the level of participation in politics of women does not change over the years (see $X_{p}$ for 2009 and 2010), the scores are different.

The arbitrariness in setting the top value of basic indicator scales may also affect the comparability of countries as reported in the example of Table 6. The derived indicator "Peace 
Table 6 Scale limits for basic indicators 'deaths from armed conflicts per year' and 'military expenditures as a percentage of GDP' (Prescott-Allen 2001)

Top values on basic indicator scale

Top points on

Bands

\section{Deaths from} armed conflicts per year
Military

expenditures as a

percentage of

GDP

\begin{tabular}{llll}
\hline Top value $=-$ & Top value $=0 \%$ & 100 & Good \\
Top value $=-$ & Top value $=2 \%$ & 80 & Fair \\
Top value $=-$ & Top value $=4 \%$ & 60 & Medium \\
Top value $=0$ & Top value $=8 \%$ & 40 & Poor \\
Top value $=1,000$ & Top value $=16 \%$ & 20 & Bad \\
Top value $=10,000$ & Top value $=32 \%$ & 0 & Base \\
\hline
\end{tabular}

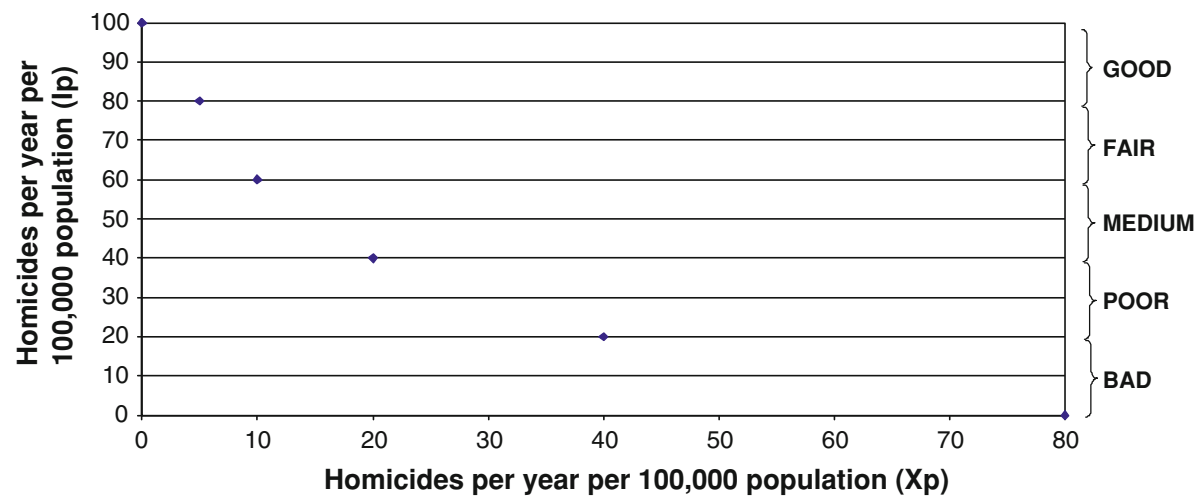

Fig. 3 Graphical representation of the exponential relation between the basic indicator 'Homicides per year per 100,000 population' and its score

Index" (a component of HWI) is obtained as the minimum between the score of "Deaths from armed conflicts per year" and "Military Expenditures as a percentage of GDP".

Observing Table 6 we see that due to the definition of the scale of basic indicator "Deaths from armed conflicts per year", the derived indicator "Peace Index" is limited to a value of 40. Countries with different levels of "Military expenditures as a percentage of GDP" but equal score of "Deaths from armed conflicts per year" may be not distinguished.

Another observation concerns the adoption of an exponential relation between some basic indicators and their scores. In Fig. 3 is reported an example on the calculation of the score "Homicide per year per 100,000 population" (a component of the HWI).

The halving of "Homicide per year rate" always corresponds to a constant band of 20 units on the Barometer scale. However, for countries with high rates of homicides per year the reduction of this indicator is probably more difficult than for the others.

Finally, a criticality concerns the scale typologies and the applied procedures of aggregation. For example, the "Corruption Perception Index" (a component of the HWI) is built on an ordinal scale and then interpolated to obtain the corresponding score. However, it should be noted that interpolation can be applied to indicators expressed at least on linear interval scales (Roberts 1979). 
Table 7 Checking of monotony property

\begin{tabular}{|c|c|c|c|c|c|}
\hline \multirow[t]{2}{*}{ Year } & \multicolumn{2}{|c|}{$\begin{array}{l}\text { Deaths from armed conflicts } \\
\text { per year }\end{array}$} & \multicolumn{2}{|c|}{$\begin{array}{l}\text { Military expenditures } \\
\text { as } \% \text { of GDP }\end{array}$} & \multirow[t]{2}{*}{$\begin{array}{l}\text { Peace Index }=\min \\
\left(\mathrm{I}_{\mathrm{p} 1}, \mathrm{I}_{\mathrm{p} 2}\right)\end{array}$} \\
\hline & $\mathrm{X}_{\mathrm{p} 1}$ & $\mathrm{I}_{\mathrm{p} 1}$ & $\mathrm{X}_{\mathrm{p} 2}$ & $\mathrm{I}_{\mathrm{p} 2}$ & \\
\hline 2000 & 0 & 40 & 3.09 & 69 & 40 \\
\hline 2001 & 0 & 40 & 3.10 & 69 & 40 \\
\hline 2002 & 0 & 40 & 3.42 & 66 & 40 \\
\hline 2003 & 0 & 40 & 3.81 & 62 & 40 \\
\hline 2004 & 0 & 40 & 4.00 & 60 & 40 \\
\hline 2005 & 0 & 40 & 4.07 & 60 & 40 \\
\hline 2006 & 0 & 40 & 4.02 & 60 & 40 \\
\hline 2007 & 0 & 40 & 4.05 & 60 & 40 \\
\hline 2008 & 0 & 40 & 4.31 & 58 & 40 \\
\hline
\end{tabular}

The growth of military expenditures over the years is not detected by the derived indicator 'Peace Index' Source of data for $\mathrm{X}_{\mathrm{p} 2}$ 'Deaths from armed conflicts per year': Uppsala Conflict Data Program; Source of data for $\mathrm{X}_{\mathrm{p} 1}$ 'Military expenditures as \% of GDP': World Bank.

\subsection{Checking of correlation among indicators}

Looking at the sub-indicators considered in the WI it is possible to individuate some correlations. For example, the "Inflation and Unemployment Index" (a component of HWI) is obtained as the minimum between the scores "Annual Inflation Rate" and "Annual Unemployment Rate". However, under suitable assumptions, it is possible to identify an empirical correlation between these scores. According to the Phillips curve, low (high) unemployment rates are associated with high (low) inflation rates (Phillips 1958).

\subsection{Checking of monotony property}

Referring to some sub-indicators, the WI does not satisfy the monotony property. Consider again the derived indicator "Peace Index" calculated as the minimum between the scores "Deaths from armed conflicts per year" and "Military Expenditures as a percentage of GDP". In Table 7 the Peace Index is calculated for USA (years 2000-2008). The growth of the military expenditures due to the well known worsening of the peace condition from 2001 is not detected by the derived indicator.

\subsection{Checking of compensation property}

The additive model (i.e. weighted or simple average) used to determine the WI and many of its component indicators (see Fig. 2) fulfils the property of compensation. This implies that countries with the same WI may be very different. As an example, in Table 8 we see that United Kingdom and Botswana have almost the same WI in 2001 but two different "Crime Indexes".

The compensation property introduces a substitution rate among component indicators in the evaluation of the Crime Index. If we consider again Table 8 we have:

$$
\Delta(\text { Robbery Score })=3 \Delta(\text { Homicide Score })
$$

When the "Homicide Score" increases, for example, of a unit, the "Crime Index" remains the same if the "Robbery Score" decreases of 3 units. There is a substitution rate between homicides and robberies in a country which may be not desirable. 
Table 8 The WI and the 'Crime Index' of United Kingdom and Botswana (Prescott-Allen 2001)

\begin{tabular}{|c|c|c|c|}
\hline \multicolumn{2}{|c|}{ Indicators } & \multicolumn{2}{|l|}{ Country } \\
\hline & & United Kingdom & Botswana \\
\hline \multicolumn{2}{|l|}{ WI } & 51.5 & 51 \\
\hline $\mathrm{I}_{\mathrm{p} 1}$ & Homicide Score & 92 & 56 \\
\hline $\mathrm{I}_{\mathrm{p} 2 \mathrm{a}}$ & Rape Score & 80 & 36 \\
\hline $\mathrm{I}_{\mathrm{p} 2 \mathrm{~b}}$ & Robbery Score & 31 & 60 \\
\hline $\mathrm{I}_{\mathrm{p} 2 \mathrm{c}}$ & Assault Score & 16 & 0 \\
\hline $\mathrm{I}_{\mathrm{p} 2}$ & Other Violent Crimes Score $1 / 3 \mathrm{I}_{\mathrm{p} 2 \mathrm{a}}+1 / 3 \mathrm{I}_{\mathrm{p} 2 \mathrm{~b}}+1 / 3 \mathrm{I}_{\mathrm{p} 2 \mathrm{c}}$ & 42.3 & 32 \\
\hline & Crime Index $1 / 2 \mathrm{I}_{\mathrm{p} 1}+1 / 2 \mathrm{I}_{\mathrm{p} 2}$ & $\begin{array}{l}67 \text { (medium, fair) } \\
\text { on the barometer } \\
\text { scale }\end{array}$ & $\begin{array}{l}44 \text { (poor, medium) } \\
\text { on the barometer } \\
\text { Scale }\end{array}$ \\
\hline
\end{tabular}

\section{Conclusions}

The inadequacy of Gross Domestic Product (GDP) as a metric of economic and social development of a country is a debated issue. The aggregate data contained in GDP do not represent what is really significant for people's well-being. In a rapidly changing context, a pragmatic, structured and objective approach of analysis to support policy makers in the definition and comparison of indicators alternative to GDP is necessary. This paper suggests a methodology able to meet this need. The recommendations of Stiglitz-Sen-Fitoussi's Report on the measurement of economic performance and social progress are adopted as the representation-target in the evaluation of the social and economic development of a country. Then a set of technical properties to be investigated in the analysis of indicators alternative to GDP are formally defined. The assessment scale of indicators, the correlation among component indicators as well as the properties of monotony, compensation and other general properties (i.e.: the level of detail, simplicity of use, long term goals and impact on stakeholders) are considered. Each property is analyzed in order to understand its effect on an indicator representativeness with respect to the considered representation target.

In order to give an application example, the paper proposes a synthetic comparison among the main alternative indicators to GDP proposed in the scientific literature basing on the described methodology. Furthermore, the procedure of analysis is developed in detail for a selected well-being indicator.

The proposed approach is suitable both for the definition of a new indicator alternative to GDP as well as for the comparison of the existing alternatives. The procedure steps are standard and may be applied independently of the specific social and economic context considered. However, the decision-maker plays an important role in the deeply understanding of the context, indicators technical properties and their effect on the representativeness of the considered indicators.

\section{References}

Bijl, R.: Never Waste a Good Crisis: Towards Social Sustainable Development. Soc. Indic. Res. (2010). doi:10. 1007/s11205-010-9736-y

Böhringer, C., Jochem, P.E.P.: Measuring the immeasurable-a survey of sustainability indices. Ecol. Econ. 63, 1-8 (2007) 
Bolt, K., Matete, M., Clemens, M.: Manual for calculating adjusted net savings. Environment Department World Bank. http://siteresources.worldbank.org/INTEEI/1105643-1115814965717/20486606/ Savingsmanual2002.pdf (2002). Accessed 13 January 2011

Brennan, A.J.: Theoretical foundations of sustainable economic welfare indicators - ISEW and political economy of the disembedded system. Ecol. Econ. 67(1), 1-19 (2008)

Cobb, C., Halstead, T., Rowe, J.: The Genuine Progress Indicator: Summary of Data and Methodology. Redefining Progress Publication, San Francisco (1995)

D’Acci, L.: Measuring Well-being and progress. Soc. Indic. Res. (2010). doi:10.1007/s11205-010-9717-1

Daly, H.E.: Steady-State Economics. W.H. Freeman, San Francisco (1977)

Daly, H.E., Cobb, J. Jr..: For the Common Good-Redirecting the Economy Toward Community, the Environment, and a Sustainable Future. Beacon Press, Boston (1989)

Franceschini, F.: Advanced Quality Function Deployment. St. Lucie Press/CRC Press LLC, Boca Raton, FL (2002)

Franceschini, F., Galetto, M., Maisano, D.: Management by Measurement: Designing Key Indicators and Performance Measurement Systems. Springer, Berlin (2007)

Hamilton, K., Atkinson, G., Pearce, D.W.: Genuine Savings as an Indicator of Sustainability. CSERGE Working Paper GEC 97-03. http://remi.bazillier.free.fr/gec_1997_03.pdf (1997). Accessed 19 December 2010

Hartwick, J.M.: Intergenerational equity and the investing of rents from exhaustible resources. Am. Econ. Rev. 67(5), 972-974 (1977)

Hicks, J.: Value and Capital. 2nd edn. Clarendon Press, London (1946)

Hueting, R.: Nieuwe Schaarste and Economische Groei. Agon Elsevier, Amsterdam (1974). English edition: New Scarcity and Economic Growth. North-Holland Publishing Company, Amsterdam, New York, Oxford (1980)

Hueting, R.: Three persistent myths in the environmental debate. Ecol. Econ. 18(2), 81-88 (1996)

Kennedy, R.F.: Remarks of Robert F. Kennedy at the University of Kansas, March 18, 1968. John F. Kennedy Presidential Library \& Museum. http://www.jfklibrary.org/Historical+Resources/Archives/ Reference+Desk/Speeches/RFK/RFKSpeech68Mar18UKansas.htm (1968). Accessed 19 December 2010

Kimura, K.: A micro-macro linkage in the measurement of inequality. Another look at the Gini coefficient. Qual. Quant. 28(1), 83-97 (1994)

Kulig, A., Kolfoort, H., Hoekstra, R.: Welfare Measurement in a National Accounting Framework. Statistics Netherlands. http://www.cbs.n1/NR/rdonlyres/48D82649-165A-4C03-9233-D43ECF241C68/0/ B31WelfaremeasurementinaNationalAccountingFramework.pdf (2007). Accessed 19 December 2010

Kuznets, S.: National Income, 1929-1932. 73rd US Congress, 2d session, Senate document no. 124, page 7. http://library.bea.gov/u?/SOD, 888 (1934). Accessed 19 December 2010

Lawn, P.A.: A theoretical foundation to support the Index of Sustainable Economic Welfare (ISEW), Genuine Progress Indicator (GPI), and other related indexes. Ecol. Econ. 44, 105-118 (2003)

Lintott, J.: Environmental accounting: useful to whom and for what?. Ecol. Econ. 16, 179-190 (1996)

Max-Neef, M.: Economic growth and quality of life: a thresold hypothesis. Ecol. Econ. 15, 115-118 (1995)

Mishan, E.J.: The Cost of Economic Growth. Staples Press, London (1967)

Natoli, R., Zuhair, S.: Measuring Progress: A Comparison of the GDP, HDI, GS and the RIE. Soc. Indic. Res. (2010). doi:10.1007/s11205-010-9695-3

Nordhaus, W.D., Tobin, J.: Is Growth Obsolete?. National Bureau of Economics. http://www.nber.org/chapters/ c7620.pdf?new_window=1 (1973). Accessed 19 December 2010

OECD Global Project on Measuring the Progress of Societies: Measuring the Progress of Societies: An Introduction and Practical Guide. http://www.oecd.org/dataoecd/23/46/44027116.pdf (2009). Accessed 19 December 2010

Pearce, D.W., Atkinson, G.: Capital theory and the measurement of sustainable development: an indicator of weak sustainability. Ecol. Econ. 8(2), 103-108 (1993)

Phillips, A.W.: The relation between unemployment and the rate of change of money wage rates in the United Kingdom, 1861-1957. Economica 25, 283-289 (1958)

Prescott-Allen, R.: The Wellbeing of Nations. Island Press, Washington (2001)

Roberts, F.S.: Measurement Theory. Addison-Wesley, Reading (1979)

Rojas, M.: The 'Measurement of economic performance and social progress' report and quality of life: moving forward. Soc. Indic. Res. (2010). doi:10.1007/s11205-010-9737-x

Sen, A.: Real national income. Rev. Econ. Stud. 43(1), 19-39 (1976)

Sen, A.: The welfare basis of real income comparisons. J. Econ. Lit. 17(1), 1-45 (1979)

Smith, R.B.: Global human development: accounting for its regional disparities. Qual. Quant. 43(1), 1-34 (2009) 
Stiglitz, J.E.: The ethical economist—a review of "The moral consequences of economic growth". By B.M. Friedman (Knopf, 2005). Foreign Aff. November/December 2005 (2005)

Stiglitz, J.E., Sen, A., Fitoussi, J.: Report by the Commission on the Measurement of Economic Performance and Social Progress. Commission on the Measurement of Economic Performance and Social Progress. http://www.stiglitz-sen-fitoussi.fr/documents/rapport_anglais.pdf (2009). Accessed 19 December 2010

Sustainable Society Foundation: Sustainable Society Index, SSI: Evaluation and Redesign. Sustainable Society Foundation. http://www.ssfindex.com/cms/wp-content/uploads/pdf/Redesign_SSI_2010. pdf (2010). Accessed 19 December 2010

Talberth, J., Cobb, C., Slattery, N.: The Genuine Progress Indicator 2006: A Tool for Sus-tainable Development. Redefining Progress. http://www.environmental-expert.com/Files\%5C $24200 \%$ 5Carticles\%5C12128\%5CGPI202006.pdf (2007). Accessed 19 December 2010

United Nations Development Programme: Human Development Report 2003. Oxford University Press, Oxford (2003)

UNEP (United Nations Environmental Programme): Integrated environmental and economic accountingan operational manual. United Nations. http://unstats.un.org/unsd/publication/SeriesF/SeriesF_78E.pdf (2000). Accessed 19 December 2010

United Nations Statistics Division: System of National Accounts-Paragraph 1.69. http://unstats.un.org/unsd/ sna1993/tocLev8.asp?L1=1\&L2=10 (1993). Accessed 20 December 2010

Van den Bergh, J.C.G.M.: Abolishing GDP. Tinbergen Institute, Amsterdam. http://www.tinbergen.nl/ discussionpapers/07019.pdf (2007). Accessed 19 December 2010

Van de Kerk, G., Manuel, A.R.: A comprehensive index for a sustainable society: The SSI-the Sustainable Society Index. Ecol. Econ. 66(2-3), 228-242 (2008) 